\author{
Marquette University \\ e-Publications@Marquette
}

8-2016

\title{
Analysis of Heme Iron Coordination in DGCR8: The Heme-Binding Component of the Microprocessor Complex
}

\author{
Hazel M. Girvan \\ Centre for Synthetic Biology of Fine and Specialty Chemicals (SYNBIOCHEM) \\ Justin M. Bradley \\ University of East Anglia \\ Myles R. Cheesman \\ University of East Anglia \\ James R. Kincaid \\ Marquette University, james.kincaid@marquette.edu \\ Yilin Liu \\ Marquette University
}

See next page for additional authors

Follow this and additional works at: https://epublications.marquette.edu/chem_fac

Part of the Chemistry Commons

\section{Recommended Citation}

Girvan, Hazel M.; Bradley, Justin M.; Cheesman, Myles R.; Kincaid, James R.; Liu, Yilin; Czarnecki, Kazimierz; Fisher, Karl; Leys, David; Rigby, Stephen E. J.; and Munro, Andrew W., "Analysis of Heme Iron Coordination in DGCR8: The Heme-Binding Component of the Microprocessor Complex" (2016).

Chemistry Faculty Research and Publications. 521.

https://epublications.marquette.edu/chem_fac/521 


\section{Authors}

Hazel M. Girvan, Justin M. Bradley, Myles R. Cheesman, James R. Kincaid, Yilin Liu, Kazimierz Czarnecki, Karl Fisher, David Leys, Stephen E. J. Rigby, and Andrew W. Munro 


\title{
Analysis of Heme Iron Coordination in DGCR8: The Heme-Binding Component of the Microprocessor Complex
}

\author{
Hazel M. Girvan, ${ }^{\dagger}$ Justin M. Bradley, ${ }^{\ddagger}$ Myles R. Cheesman, ${ }^{\ddagger}$ James R. Kincaid, ${ }^{\S}$ Yilin Liu, ${ }^{\S}$
} Kazimierz Czarnecki, ${ }^{\S}$ Karl Fisher, ${ }^{\dagger}$ David Leys, ${ }^{\dagger}$ Stephen E. J. Rigby, ${ }^{\dagger}$ and Andrew W. Munro* ${ }^{\dagger}$

${ }^{\dagger}$ Centre for Synthetic Biology of Fine and Specialty Chemicals (SYNBIOCHEM), Manchester Institute of Biotechnology, Faculty of Life Sciences, University of Manchester, 131 Princess Street, Manchester M1 7DN, U.K.

${ }^{\ddagger}$ School of Chemistry, University of East Anglia, Norwich Research Park, Norwich NR4 7TJ, U.K.

${ }^{\S}$ Department of Chemistry, Marquette University, 535 North 14th Street, Milwaukee, Wisconsin 53233, United States

\section{Supporting Information}

ABSTRACT: DGCR8 is the RNA-binding partner of the nuclease Drosha. Their complex (the "Microprocessor") is essential for processing of long, primary microRNAs (primiRNAs) in the nucleus. Binding of heme to DGCR8 is essential for pri-miRNA processing. On the basis of the split Soret ultraviolet-visible (UV-vis) spectrum of ferric DGCR8, bis-thiolate sulfur (cysteinate, $\mathrm{Cys}^{-}$) heme iron coordination of DGCR8 heme iron was proposed. We have characterized DGCR8 heme ligation using the $\Delta 276$ DGCR8 variant and combined electron paramagnetic resonance (EPR), magnetic circular dichroism (MCD), electron nuclear double resonance,

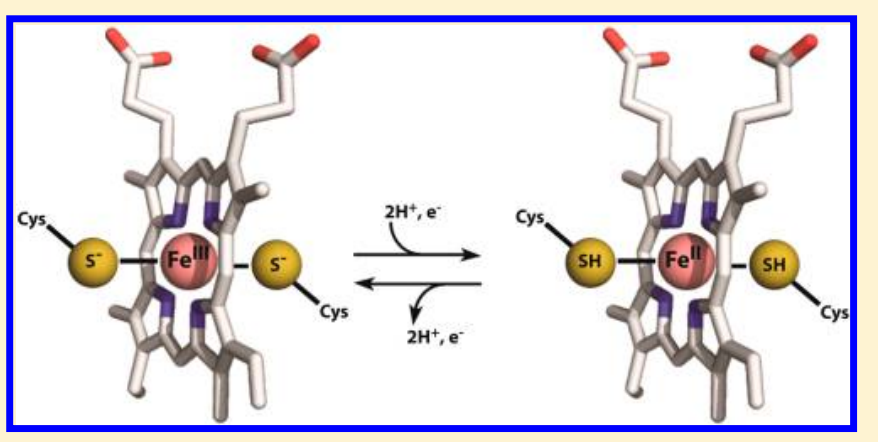
resonance Raman, and electronic absorption spectroscopy. These studies indicate DGCR8 bis-Cys heme iron ligation, with conversion from bis-thiolate $\left(\mathrm{Cys}^{-} / \mathrm{Cys}^{-}\right)$axial coordination in ferric DGCR8 to bis-thiol (CysH/CysH) coordination in ferrous DGCR8. Pri-miRNA binding does not perturb ferric DGCR8's optical spectrum, consistent with the axial ligand environment being separated from the substrate-binding site. UV-vis absorption spectra of the $\mathrm{Fe}^{\mathrm{II}}$ and $\mathrm{Fe}^{\mathrm{II}}-\mathrm{CO}$ forms indicate discrete species exhibiting peaks with absorption coefficients substantially larger than those for ferric DGCR8 and that previously reported for a ferrous form of DGCR8. Electron-nuclear double resonance spectroscopy data exclude histidine or water as axial ligands for ferric DGCR8 and favor bis-thiolate coordination in this form. UV-vis MCD and near-infrared MCD provide data consistent with this conclusion. UV-vis MCD data for ferrous DGCR8 reveal features consistent with bis-thiol heme iron coordination, and resonance Raman data for the ferrous-CO form are consistent with a thiol ligand trans to the CO. These studies support retention of DGCR8 cysteine coordination upon reduction, a conclusion distinct from those of previous studies of a different ferrous DGCR8 isoform.

$\mathrm{M}$ icroRNAs (miRNAs) make up a large family of short ( 22-nucleotide) noncoding RNAs with fundamental roles in the regulation of cellular function in animals and plants and in certain viruses. Most animal miRNAs base pair (imperfectly) to sequence regions in the $3^{\prime}$-untranslated region (UTR) of their target mRNAs. ${ }^{1}$ In so doing, they cause inhibition of protein synthesis by either repressing translation or promoting the deadenylation and degradation of the mRNA. $^{2-5}$ The crucial importance of miRNAs in gene regulation is now well understood, and it is thought that miRNAs control the activity of more than half of all mammalian protein-coding genes. ${ }^{1}$

In the canonical route for their production, miRNAs are synthesized in a multistage pathway that begins in the nucleus with transcription of long (often kilobase) primary miRNA (pri-miRNA) species by RNA polymerase II, usually with both a $5^{\prime}$ cap and a poly-A tail. ${ }^{6,7}$ Pri-miRNA has an $\sim 80$-base hairpin, flanked at both the $3^{\prime}$ and $5^{\prime}$ ends by single-stranded RNA. ${ }^{8}$ These pri-miRNA transcripts are cleaved into shorter
( $\sim 65$-nucleotide) precursor miRNA (pre-miRNA) hairpins ${ }^{9,10}$ by the RNase III enzyme Drosha. ${ }^{11}$ Drosha is incapable of primiRNA cleavage in isolation, instead working as part of the Microprocessor complex with DGCR8 (DiGeorge critical region 8 protein). ${ }^{12-15}$ Drosha contains two RNase III domains (RIIIDa and RIIIDb) that cleave the $3^{\prime}$ strand and $5^{\prime}$ strand of the pre-miRNA, respectively, leaving an overhang on the $3^{\prime}$ protruding end for recognition by Exportin 5. ${ }^{10,11}$ Following nuclear export by Exportin 5, the pre-miRNA is further cleaved by the RNase III enzyme Dicer, forming a 22-nucleotide miRNA:miRNA* duplex. ${ }^{16-18}$ One strand of the duplex remains as the mature miRNA, becoming incorporated into the miRISC (miRNA-induced silencing complex), ${ }^{19,20}$ where the miRNA base pairs to target mRNA, usually in the $5^{\prime}$ UTR

Received: March 4, 2016

Revised: August 19, 2016

Published: August 20, 2016 
( $5^{\prime}$-untranslated region), inducing either translational repression or mRNA degradation. ${ }^{2-5}$ The other strand (the "passenger" miRNA, or miRNA*) is typically released and degraded but can also be incorporated into the miRISC complex and function as a bona fide miRNA. ${ }^{21-23}$ Alternative routes for miRNA biogenesis that do not rely on one or both of the Microprocessor or Dicer systems have been discovered. ${ }^{24}$ For example, in the mirtron pathway, short hairpins are generated with splice acceptor and donor sites, and a splicing event replaces the Drosha cleavage step before the pathway continues as described above. Alternatively, miRNA synthesis can occur in a Microprocessor-dependent, Dicer-independent manner in which pre-miRNA is loaded into Argonaute (a catalytic component of the miRISC complex) and in which a number of further cleavage steps ultimately result in miRNA formation. $^{1,24}$

The processing of long pri-miRNA transcripts into shorter pre-miRNAs by the Microprocessor complex is a key step in the canonical pathway of miRNA generation. The Drosha RNase III is crucial for nuclear miRNA processing and is a key component of the Microprocessor. ${ }^{11}$ However, it is incapable of miRNA cleavage without its DGCR8 partner. ${ }^{12-15}$ DGCR8 is a 773-amino acid protein that contains two dsRNA-binding domains at the C-terminus ${ }^{25}$ and a WW motif ${ }^{13}$ and also binds a heme prosthetic group. ${ }^{26}$ DGCR8 can be truncated into an active form named NC1 (amino acids 276-751) that contains both the heme-binding domain (HBD, amino acids 276-498) and two double-stranded RNA-binding domains (amino acids 499-751) followed by a short tail region. ${ }^{10}$ A dimerization domain was also identified within the independently folded HBD (amino acids 276-353), and its crystal structure was determined in a dimeric state. These data revealed a key role for the WW motif region in formation of the domain-swapped dimer and implicated this region in association with the heme cofactor in DGCR8. ${ }^{27}$ The dsRNA-binding domains of DGCR8 form the binding site for pri-miRNA, ${ }^{8}$ and the Cterminal region is responsible for Drosha's interactions with DGCR8. ${ }^{28}$ DGCR8 and Drosha are the minimum requirement for the processing of pri-miRNA to pre-miRNA. ${ }^{13,15}$ However, other proteins, including p53 and nucleolin, bind to the Microprocessor complex to influence its activity, by either increasing or decreasing the rate of processing of a subset of miRNAs. ${ }^{29,30}$ Heme-bound DGCR8 is essential for the catalytic function of the Microprocessor complex. ${ }^{31}$ Quick-Cleveland et al. showed that the HBD is crucial for the binding and recognition of pri-miRNA by DGCR 8 and that heme is essential for producing processing-competent DGCR8/primiRNA complexes. ${ }^{32}$

Early studies proposed that axial coordination of DGCR8 heme $b$ came from a cysteine residue, ${ }^{26}$ potentially making DGCR8 a member of the growing class of heme thiolate proteins. Other notable heme thiolate proteins are the widely studied cytochrome P450 (P450 or CYP) monooxygenases and the nitric oxide synthases that catalyze oxidative transformation of L-arginine to L-citrulline and nitric oxide. ${ }^{33}$ Numerous examples of heme thiolate proteins have been discovered with diverse functions. These include the heme sensors Rev-erb $\alpha$ and $\operatorname{Rev}-\operatorname{erb} \beta$, which are nuclear receptors and transcriptional repressors and bind heme to allow interaction with corepressor proteins and to regulate transcription in circadian rhythm pathways. ${ }^{34}$ Another example is the CO-sensing transcription factor CooA from Rhodospirillum rubrum, a bacterium that uses $\mathrm{CO}$ as a carbon source under anaerobic conditions. CooA uses a ligand switching mechanism whereby a cysteine ligand to the heme iron is displaced by a histidine when the heme iron is reduced. In the dimeric CooA structure, the other axial ligand comes from the $\mathrm{N}$-terminal proline of the opposite monomer. This proline is displaced by $\mathrm{CO}$, and the structural change induced permits the exposure of DNA-binding domains in CooA. The transcriptionally competent CooA can then activate the expression of genes required for oxidation of $\mathrm{CO}$ to $\mathrm{CO}_{2}$ and for the reduction of protons to $\mathrm{H}_{2} \cdot{ }^{34,35}$

Previous studies of DGCR8 reported that Cys352 is involved in heme binding, although the identity of the axial ligand trans to the cysteine was not identified. ${ }^{26}$ Barr et al. then reported spectroscopic data consistent with bis-cysteine ligation of the heme iron and suggested that a single heme was coordinated by Cys352 side chains from both DGCR8 proteins in a dimer. The ferric heme form was later identified as being crucial for primiRNA processing, with the ferrous heme form being inactive and exhibiting an increased rate of dissociation of heme from the protein. In the previous study, the axial coordination state of the frog DGCR8-bound ferrous heme was not clearly established, but it was inferred that cysteine ligation was lost and that the ferrous heme might exist in heterogeneous spin and coordination states. ${ }^{36}$ In this study, we report a detailed analysis of the heme-binding site of DGCR8 using a range of spectroscopic techniques. The results allow us to assign the active ferric heme form of the human DGCR8 protein as the first bis-Cys-ligated protein and to provide data supporting the retention of cysteine coordination of the heme iron in the ferrous form of this physiologically important enzyme.

\section{EXPERIMENTAL PROCEDURES}

DCGR8 Cloning, Overexpression, and Purification. The DGCR8 gene was obtained as Addgene plasmid 10921 from the Tuschl group. ${ }^{15}$ A 276-N-terminal amino acid truncation was generated by polymerase chain reaction (PCR), with mutagenic oligonucleotides creating an NdeI restriction enzyme site at the new start codon and a downstream BglII site in the $3^{\prime}$ oligonucleotide (forward primer 5 '-ggcggagacagcgaccatcatatggatggagagacaagtg- $3^{\prime}$ and reverse primer $5^{\prime}$-ctagatatctcgagatctgccgctcacacgtccacggtgcacag-3', where NdeI and BglII sites are underlined in the forward and reverse primer, respectively). The PCR product was then cloned into pET15b, which provides a six-His Nterminal tag to the truncated DGCR8, and the correct DNA sequence was verified by complete sequencing of the cloned gene (Source BioScience, Rochdale, U.K.).

The $\Delta 276$ DGCR8 (the 276-N-terminal amino acid truncated form of DGCR8) was expressed in Escherichia coli BL21(DE3) cells. Transformant cell cultures were grown while being shaken at $37{ }^{\circ} \mathrm{C}$ until an $\mathrm{OD}_{600}$ of 0.8 was reached. The incubation temperature was then decreased to $18{ }^{\circ} \mathrm{C}$ and DGCR8 gene expression induced by addition of $0.25 \mathrm{mM}$ isopropyl $\beta$-D-1-thiogalactopyranoside (IPTG), along with $\delta$ aminolevulinic acid $(0.2 \mathrm{mM})$ to promote heme synthesis and incorporation. Cultures were harvested by centrifugation following cell growth for a further $18 \mathrm{~h}$ post-IPTG induction. Bacterial cells were resuspended in $50 \mathrm{mM}$ Tris $(\mathrm{pH} \mathrm{8.0)}$ and $200 \mathrm{mM} \mathrm{KCl}$ buffer at $4{ }^{\circ} \mathrm{C}$ (binding buffer). The cells were lysed by sonication using a Bandelin Sonopuls sonicator (10 passes at $40 \%$ full power), and DGCR 8 was purified by affinity chromatography, using nickel-NTA resin (Generon, Maidenhead, U.K.) as a first step. The protein was bound to the column, washed in binding buffer, and then eluted with binding 
buffer and $100 \mathrm{mM}$ imidazole. The protein was exchanged into binding buffer and loaded onto a heparin Sepharose 6 Fast Flow column (GE Healthcare, Little Chalfont, U.K.), prior to elution with binding buffer with $500 \mathrm{mM} \mathrm{KCl}$. Pure DGCR8 protein was obtained using a final gel filtration step on a 16/600 S200 gel filtration column (GE Healthcare), with the same binding buffer. Purity was assessed by sodium dodecyl sulfatepolyacrylamide gel electrophoresis using a Mini-PROTEAN TGX Stain-Free 10\% gel system (Bio-Rad, Hemel Hempstead, U.K.) and by ultraviolet-visible (UV-vis) spectroscopic comparison between total protein absorbance $\left(A_{280}\right)$ and the specific DGCR8 heme absorbance $\left(A_{450}\right)$.

Preparation of RNA. The 63-nucleotide pre-miR30a and 151-nucleotide pri-miR30a complementary DNAs were synthesized (Eurofins, Ebersberg, Germany) on the basis of sequences detailed in the miRBase database ${ }^{37}$ and as described by Lee et al. ${ }^{11}$ for pre- and pri-miR30a, respectively. DNA was cloned into a plasmid containing a $3^{\prime}$ hepatitis delta virus (HDV) ribozyme for the generation of transcripts without heterogeneous $3^{\prime}$ ends. ${ }^{38}$ Plasmids were linearized with $\mathrm{XbaI}$, the site for which is downstream of the HDV ribozyme, and in vitro transcription was conducted by the method of Gurevich. ${ }^{39}$ Transcripts were dialyzed to remove salt and free nucleotides, reconcentrated by ultrafiltration using a 30000 molecular weight cutoff Vivaspin (Sartorius, Goettingen, Germany), and purified from the HDV ribozyme by electrophoresis on a $12 \%$ acrylamide, 50\% urea gel. The relevant RNA band was visualized by RNA shadowing, excised from the gel, and then purified by the crush and soak method. ${ }^{40}$

UV-Vis Spectroscopy. All UV-vis spectral measurements were made on a Cary 50 Bio spectrophotometer (Varian) with a $1 \mathrm{~cm}$ path length cuvette. Unless otherwise stated, all spectra were recorded in $50 \mathrm{mM}$ Tris $(\mathrm{pH} 8.0)$ and $500 \mathrm{mM} \mathrm{KCl}$ containing $10 \%$ glycerol at $20^{\circ} \mathrm{C}$. The DGCR 8 heme content was quantified using a coefficient $\varepsilon_{450}$ of $70 \mathrm{mM}^{-1} \mathrm{~cm}^{-1}$ for the oxidized (ferric) hemoprotein. This value was calculated using the pyridine hemochromagen method. ${ }^{41}$

Magnetic Circular Dichroism (MCD) Spectroscopy. MCD spectra were recorded using JASCO J/810 and J/730 spectropolarimeters in the UV-vis and near-IR (NIR) regions, respectively, at $20{ }^{\circ} \mathrm{C}$. A magnetic field of $6 \mathrm{~T}$ was generated using an Oxford Instruments superconducting solenoid with a $25 \mathrm{~mm}$ ambient bore. A $0.1 \mathrm{~cm}$ path length quartz cuvette was used to record near-IR spectra with a $70 \mu \mathrm{M}$ DGCR8 sample in $50 \mathrm{mM}$ Tris (pH 8.0), $500 \mathrm{mM} \mathrm{KCl}$, and 10\% glycerol. UV-vis spectra were also recorded for a $70 \mu \mathrm{M}$ sample, but here using buffer prepared in deuterium oxide (otherwise as described above) and following extensive dialysis of the sample into the deuterated buffer. A reduced DGCR8 sample was prepared by adding sodium dithionite to a $185 \mu \mathrm{M}$ sample of DGCR8 in an anaerobic glovebox environment. After incubation for $4 \mathrm{~h}$ at 20 ${ }^{\circ} \mathrm{C}$ to ensure extensive reduction of the DGCR8 heme iron, electronic absorption and MCD spectra were recorded in the UV-vis region. Minor spectral contributions from residual amounts of ferric DGCR8 $(\sim 15 \%)$ were accounted for by determining the proportion of ferric DGCR8 (with reference to the oxidized DGCR8 spectrum) and by subtracting this component from the obtained ferrous DGCR8 spectrum.

Electron Paramagnetic Resonance (EPR) and Electron-Nuclear Double Resonance (ENDOR) Spectroscopic Analysis of DGCR8. Spectra were recorded at $10 \mathrm{~K}$ and X-band $(\sim 9.5 \mathrm{GHz})$ using a Bruker ELEXSYS E500/E580 spectrometer equipped with a Bruker ER 4123SHQE resonator together with an Oxford Instruments ESR900 cryostat for EPR measurements, and a Bruker EN 4118X-MD-4 resonator together with an Oxford instruments CF935 cryostat for ENDOR measurements. DGCR8 spectra of a $225 \mu \mathrm{M}$ sample in $50 \mathrm{mM}$ Tris $(\mathrm{pH} 8.0), 500 \mathrm{mM} \mathrm{KCl}$, and $10 \%$ glycerol were recorded. A sample was also exchanged into deuterated buffer of the same composition by extensive dialysis, and an ENDOR spectrum was then recorded at the same protein concentration used for the nondeuterated sample. EPR experiments were conducted using a $1 \mathrm{~mW}$ microwave power and a $5 \mathrm{G}$ modulation amplitude at a modulation frequency of $100 \mathrm{kHz}$. The ENDOR experiments employed a Davies echo-detected pulse sequence, ${ }^{42}$ inversion $-T-\pi / 2-\tau-\pi-\tau-$ acquire, with the $9 \mu$ s radiofrequency pulse applied during the $10 \mu \mathrm{s} T$ period. For ${ }^{14} \mathrm{~N}$ spectra, the inversion pulse was $600 \mathrm{~ns}$ with a $\pi$ of 120 ns and a $\tau$ of 600 ns. For ${ }^{1} \mathrm{H}$ spectra, the inversion pulse was $400 \mathrm{~ns}$ with a $\pi$ of $200 \mathrm{~ns}$ and a $\tau$ of $1000 \mathrm{~ns}$. The static field was $2650 \mathrm{G}, g=2.61$. Each spectrum is the sum of 600 scans. Further EPR spectra (under the same conditions) were recorded for a $100 \mu \mathrm{M}$ DGCR8 sample and for a $100 \mu \mathrm{M}$ $\mathrm{CuSO}_{4}$ sample to allow independent determination of the DGCR8 concentration and its absorption coefficient in the UV-vis spectrum.

Resonance Raman Spectroscopic Analysis of DGCR8. Sample Preparation. The concentration of the ferric DGCR8 sample used was $85 \mu \mathrm{M}$ in $50 \mathrm{mM}$ Tris ( $\mathrm{pH} 8.0$ ), $500 \mathrm{mM} \mathrm{KCl}$, and $10 \%$ glycerol. The $50 \mu \mathrm{L}$ ferric sample was transferred into an NMR tube for measurements. The ferrous DGCR8, dissolved in the glycerol-containing buffer, was then generated by first degassing the DGCR8 sample under $\mathrm{O}_{2}$-free nitrogen before adding a 20 -fold molar excess of sodium dithionite and the redox mediators methyl viologen (MV) and benzyl viologen (BV) to final concentrations of 0.3 and $1 \mu \mathrm{M}$, respectively; these additives were dissolved in the same glycerol-containing buffer. Reduction of the hemoprotein was monitored by electronic absorption spectrophotometry in the $\mathrm{UV}$-vis region at $20^{\circ} \mathrm{C}$, noting that full reduction required up to $1 \mathrm{~h}$. The $\mathrm{Fe}^{\mathrm{II}}-\mathrm{CO}$ complex was then prepared by saturation of a sample of DGCR8 with CO prior to the addition of dithionite and the $\mathrm{BV}$ and $\mathrm{MV}$ mediators (as done for the ferrous, CO-free sample). Complete formation of the DGCR8 $\mathrm{Fe}^{\mathrm{II}}-\mathrm{CO}$ complex was ensured by monitoring the electronic absorption spectrum. A second sample of ferric DGCR8 was prepared in glycerol-free buffer and studied in an effort to resolve an apparent conflict with previous reports regarding spin-state populations (vide infra). ${ }^{36}$ This second sample was prepared by adding $50 \mu \mathrm{L}$ of glycerol-free $50 \mathrm{mM}$ Tris $(\mathrm{pH}$ $8.0)$, $500 \mathrm{mM} \mathrm{KCl}$ buffer to $50 \mu \mathrm{L}$ of the sample in the $10 \%$ glycerol-containing buffer contained in a centrifugal filter cartridge (10K molecular weight cutoff) and by concentrating the $100 \mu \mathrm{L}$ resulting solution to $\sim 50 \mu \mathrm{L}$ using a microcentrifuge at $8000 \mathrm{rpm}$ and $4{ }^{\circ} \mathrm{C}$. This process was repeated eight times to ensure the buffer was completely exchanged.

Resonance Raman Measurements. The ferric DGCR8 samples were measured with the $441.6 \mathrm{~nm}$ excitation line from a $\mathrm{He}-\mathrm{Cd}$ laser (IK Series $\mathrm{He}-\mathrm{Cd}$ laser, Kimmon Koha Co. Ltd.), while the ferrous DGCR8 sample was measured with the $415 \mathrm{~nm}$ line provided by a $\mathrm{Kr}^{+}$laser (Coherent Innova Sabre Ion Laser). The spectra of the $\mathrm{Fe}^{\mathrm{II}}-\mathrm{CO}$ adducts were also recorded with the $441.6 \mathrm{~nm}$ line. The RR spectra of all samples were measured using a Spex 1269 spectrometer equipped with a Spec-10 LN liquid nitrogen-cooled detector (Princeton Instruments, Princeton, NJ). The slit width was $150 \mu \mathrm{m}$, and 


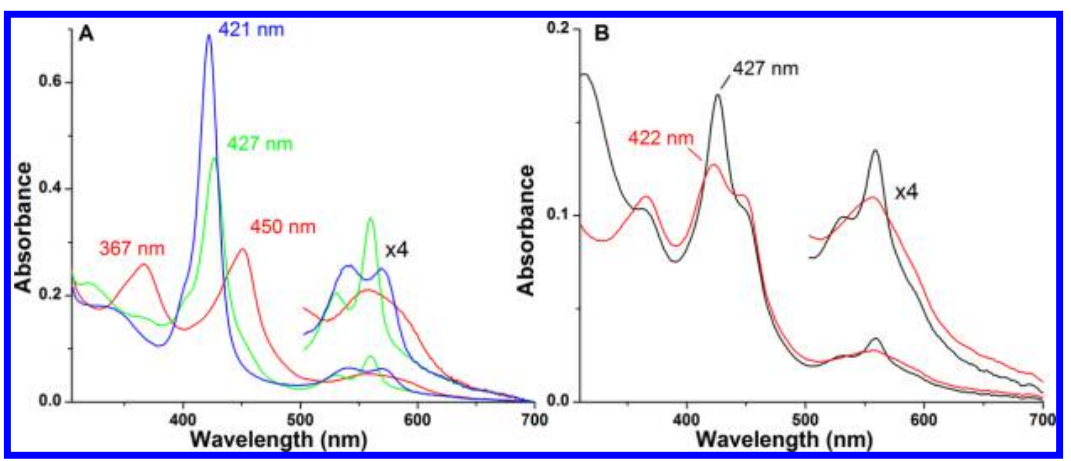

Figure 1. UV-vis absorption properties of the human $\Delta 276$ DGCR8 protein. (A) Oxidized DGCR8 (4.1 $\mu \mathrm{M}$, red line) with split Soret features and maxima at 450 and $367 \mathrm{~nm}$. There is a broad, low-intensity feature in the Q-band region stretching from 530 to $630 \mathrm{~nm}$. Upon reduction of the sample with sodium dithionite, a single Soret feature is seen at $427 \mathrm{~nm}$, with asymmetric bands in the visible region at 531 and $559 \mathrm{~nm}$ (green line). The binding of carbon monoxide to the reduced DGCR8 protein produces the Fe ${ }^{\mathrm{II}}-\mathrm{CO}$ complex with its Soret maximum at $421 \mathrm{~nm}$ and a partial merging of visible bands to give peaks at approximately 540 and $570 \mathrm{~nm}$ (blue line). (B) Partially reduced DGCR8 sample (6 $\mu \mathrm{M}$, black line), with a Soret maximum at $427 \mathrm{~nm}$ and visible region bands at 529 and $559 \mathrm{~nm}$. The binding of $\mathrm{O}_{2}$ results in a $5 \mathrm{~nm}$ shift to a Soret maximum of $422 \mathrm{~nm}$ with merging of the visible bands (peak at $557 \mathrm{~nm}$, red line). The ferrous-oxy DGCR8 rapidly collapses back to the ferric form, and a shoulder at $450 \mathrm{~nm}$ is apparent in the spectrum of the $\mathrm{O}_{2}$-bound form, consistent with a mixture of ferric and ferrous-oxy species. The ferrous-oxy UV-vis spectrum was recorded by stopped-flow spectroscopy $25 \mathrm{~ms}$ after the reduced sample had been mixed with $\mathrm{O}_{2}$-saturated buffer.

the laser power was adjusted to $\sim 30 \mathrm{~mW}$ at the laser for the ferric and ferrous samples; a power of $\sim 1 \mathrm{~mW}$ was maintained for the $\mathrm{CO}$ adducts to minimize photodissociation. All samples were measured in a spinning NMR tube to prevent local heating and protein degradation. The spectra were recorded using a $180^{\circ}$ backscattering geometry, and the laser power was focused on the sample with a line image using a cylindrical lens. Spectra were calibrated with data acquired for fenchone and processed with Grams/32 AI software (Galactic Industries, Salem, NH). Data were collected at $4 \pm 2{ }^{\circ} \mathrm{C}$ by placing the samples in a homemade quartz Dewar flask filled with cold water and monitoring during the measurements using a thermocouple.

\section{RESULTS AND DISCUSSION}

Expression and Purification of Human DGCR8. The $\Delta 276$ form of DGCR $8^{26}$ was purified to homogeneity as described in Experimental Procedures. Some nucleotide contamination (as evidenced by an absorbance feature at 260 $\mathrm{nm}$ ) was seen in the protein eluted from the nickel affinity column at a high $(500 \mathrm{mM})$ imidazole concentration, but this spectral feature was not observed for the portion of DGCR8 protein eluted in $100 \mathrm{mM}$ imidazole. Protein was further purified by heparin affinity and Sepharose S200 gel filtration chromatography steps.

UV-Vis Spectroscopic Analysis of DGCR8. In its oxidized (ferric) state, the purified DGCR8 hemoprotein has a hyperporphyrin UV-vis absorption spectrum similar to that described previously, ${ }^{26}$ with the main Soret peak at $450 \mathrm{~nm}$ and the second feature at $367 \mathrm{~nm}$. In the visible region, the ferric heme exhibits a broad absorption feature with a peak at $\sim 557$ $\mathrm{nm}$ and a shoulder at $\sim 586 \mathrm{~nm}$ (Figure 1A). In previous studies on the cysteine thiolate-coordinated camphor hydroxylase P450cam by Sono et al., the P450 was titrated with the sulfur donor ligand $p$-chlorothiophenol, generating a ferric bis-Cys heme-ligated model complex, resulting in the formation of a hyperporphyrin spectrum with Soret maxima at 380 and 450 nm. ${ }^{43}$ Further studies of the binding of 1-propanethiol to P450cam at $\mathrm{pH} 6.7$ revealed three absorbance peaks in the Soret region at approximately 380,417 , and $465 \mathrm{~nm}$, indicative of a mixture of axial bis-thiolate (the 380 and $465 \mathrm{~nm}$ bands) and thiolate/thiol coordination (the $417 \mathrm{~nm}$ band). Increasing the $\mathrm{pH}$ resulted in the nearly complete conversion of the 1propanethiol-bound species to the hyperporphyrin $380 \mathrm{~nm} / 465$ $\mathrm{nm}$ form at $\mathrm{pH} 9.1$, arising from the deprotonation of the distal ligand to the thiolate state. ${ }^{43}$ In studies using porphyrin model complexes, Ullrich et al. also reported bis-thiolate complexes with split Soret features and absorption maxima at $\sim 470$ and $380 \mathrm{~nm}^{44}$ More recent studies with the $\operatorname{RDX}(1,3,5-$ trinitroperhydro-1,3,5-triazine) explosive-degrading P450 XplA (CYP177A1) showed that titration with dithiothreitol produced a mixture of bis-thiolate (the main species, with maxima at $\sim 374$ and $453 \mathrm{~nm}$ ) and thiol-thiolate $(423 \mathrm{~nm})$ sixcoordinated forms. Similar binding studies using $\beta$-mercaptoethanol show predominantly the thiol-thiolate form of XplA at $\mathrm{pH} 6$ (at $\sim 420 \mathrm{~nm}$ ). However, under more basic conditions ( $\mathrm{pH} 8)$, the hyperporphyrin, bis-thiolate spectrum dominates with maxima at $\sim 372$ and $453 \mathrm{~nm}^{45}$ Comparison of the UVvis spectrum of ferric DGCR8 with these data suggests that heme coordination in DGCR8 occurs with cysteines in their thiolate form providing both the proximal and distal ligands, in agreement with published data. ${ }^{46}$ A DGCR8 absorption coefficient $\varepsilon_{450}$ of $70 \mathrm{mM}^{-1} \mathrm{~cm}^{-1}$ was calculated for its most intense heme absorbance band using the pyridine hemochromagen method. ${ }^{41}$ An independent determination of the DGCR8 absorption coefficient $\left(70 \pm 2 \mathrm{mM}^{-1} \mathrm{~cm}^{-1}\right)$ was obtained using X-band EPR with reference to the spectrum of a $\mathrm{CuSO}_{4}$ standard and the UV-vis absorbance spectrum of the same protein sample. This coefficient is consistent with an estimate from Senturia et al. $\left(74 \mathrm{mM}^{-1} \mathrm{~cm}^{-1}\right.$ for the human $\mathrm{NC} 1$ and HBD constructs) and with those of the frog and bat star (starfish) orthologs that have absorption coefficients of 72 and $70 \mathrm{mM}^{-1} \mathrm{~cm}^{-1}$, respectively. ${ }^{47}$

DGCR8 Heme Ligation in the Ferrous State. Reduction of the ferric DGCR8 heme iron to the ferrous state [using the strong reductant sodium dithionite, $E^{\circ} \sim-420 \mathrm{mV}$ vs the normal hydrogen electrode (NHE)] progressed slowly to completion at $20^{\circ} \mathrm{C}$, although the rate of heme reduction was enhanced upon addition of the electron transfer mediators benzyl viologen (BV) and methyl viologen (MV), suggesting that access of the reductant to the protein-bound heme may be restricted. In an anaerobic environment in the presence of BV 
and MV and with excess dithionite, the complete reduction of the ferric DGCR8 heme iron occurs at $20{ }^{\circ} \mathrm{C}$ over a period of approximately $10 \mathrm{~min}$. In the reduced (ferrous) form, DGCR8 exhibits a Soret maximum at $427 \mathrm{~nm}$ with absorbance bands in the visible region at 531 and $559 \mathrm{~nm}$. There is also an increase in the absorption coefficient for the ferrous Soret band from 70 $\mathrm{mM}^{-1} \mathrm{~cm}^{-1}$ for the oxidized protein $\left(\varepsilon_{450}\right)$ to $112 \mathrm{mM}^{-1} \mathrm{~cm}^{-1}$ in the reduced state $\left(\varepsilon_{427}\right)$ (Figure 1A). Dawson's group conducted spectroscopic investigations of heme axial coordination using a mutated myoglobin with no axial heme coordination from the polypeptide. Using either cyclopentanethiol to mimic bis-cysteine coordination ${ }^{48}$ or imidazole to mimic histidine coordination, ${ }^{49}$ they determined the spectroscopic properties of these complexes. In both cases, the addition of the neutral ligand yields a UV-vis spectrum with properties similar to those of the spectrum of the ferrous $\Delta 276$ DGCR8 protein, suggesting that, in the ferrous state, DGCR8 is coordinated by neutral axial ligand or ligands, prospectively through $\mathrm{CysH} / \mathrm{CysH}$ coordination.

In the ferrous state, the DGCR8 heme iron binds CO, producing a UV-vis spectrum with a Soret maximum of substantially increased intensity at $422 \mathrm{~nm}\left(\varepsilon_{422}=168 \mathrm{mM}^{-1}\right.$ $\mathrm{cm}^{-1}$ ) (Figure 1A). Once the sample is reduced to the ferrous state, binding of $\mathrm{CO}$ occurs rapidly, forming a complex that remains stable for several hours in either an aerobic or anaerobic environment. In cytochrome P450 enzymes (P450s), the binding of $\mathrm{CO}$ to the ferrous heme iron gives a characteristic Soret band spectral shift to $\sim 450 \mathrm{~nm}$ that results from cysteine thiolate coordination trans to the CO. However, in various $\mathrm{P} 450 \mathrm{~s}$, the ferrous-CO complex can have a Soret feature around $420 \mathrm{~nm}$ (the P420 state), which is generally considered to be the species arising from protonation of the proximal thiolate ligand to the thiol form. ${ }^{48}$ Favoring this conclusion are data such as the reversible titration of P450 to $\mathrm{P} 420$ in the $\mathrm{pH}$ range from $\sim 5$ to 9 for the Mycobacterium tuberculosis CYP121A1 enzyme and the rapid conversion of $\mathrm{P} 450$ to $\mathrm{P} 420$ in the $M$. tuberculosis sterol demethylase CYP51B1, because of the instability of the proximal thiolate to protonation in the ferrous form of the enzyme. ${ }^{50-52}$ However, heme-binding proteins with an axial histidine ligand to their heme iron also have a similar spectrum in their ferrous$\mathrm{CO}$ bound states (e.g., the hemoglobin $\mathrm{Fe}^{\mathrm{II}}-\mathrm{CO}$ complex has a Soret maximum at $420 \mathrm{~nm}$ ). Indeed, it has been proposed that in the P450s the cytochrome P420 form may result from a proximal ligand switch from cysteine thiolate to a neutral histidine-coordinated state. ${ }^{53}$ The absence of a Soret band at $450 \mathrm{~nm}$ thus strongly suggests that in its ferrous, CO-bound state the DGCR8 heme iron is not coordinated to the protein by a thiolate ligand but instead via a neutral thiol or a histidine. With reference to the aforementioned studies of P450 enzymes, the DGCR8 ferrous-CO complex is most likely to have a cysteine thiol ligand trans to the $\mathrm{CO}$. As described below, the results from RR studies are also consistent with this conclusion.

The binding of nitric oxide (NO) was also investigated for both the ferrous and ferric forms of DGCR8 under anaerobic conditions. In ferric DGCR8, no evidence of binding was seen, consistent with DGCR8 being hexacoordinate in this oxidation state (four equatorial ligands from heme pyrrole nitrogens and two axial ligands from DGCR8 amino acid side chains) and with NO being unable to displace either axial ligand. In the ferrous heme iron state, the binding of $\mathrm{NO}$ was investigated by stopped-flow UV-vis spectroscopy at $4{ }^{\circ} \mathrm{C}$. One syringe contained NO-saturated buffer $(\sim 1.9 \mathrm{mM})$, while the other contained ferrous DGCR8. As with ferric DGCR8, no evidence of a NO-bound form was found, but instead, the collapse of the DGCR8 ferrous species to the ferric state was observed as a shift in the Soret maximum from 427 to $450 \mathrm{~nm}$, with an isosbestic point $(442 \mathrm{~nm})$ between the two forms. These data suggest that a short-lived ferrous-NO species is formed transiently, but that it is unstable and rapidly decays to form the ferric DGCR8 state in $\sim 5 \mathrm{~s}$. The binding of dioxygen $\left(\mathrm{O}_{2}\right)$ to the ferrous $\Delta 276$ DGCR8 was also explored in the same manner employed for NO binding. In this case, the formation of an oxy complex was observed, with a Soret maximum at 423 $\mathrm{nm}$. However, this species was also unstable and converted rapidly back to the ferric resting state, likely by dissociation of superoxide from the heme iron (Figure 1B).

In other studies, the UV-vis spectrum of the ferric form of DGCR8 was examined as a function of temperature in the range between 20 and $-80^{\circ} \mathrm{C}$. However, no significant spectral shifts were observed for the ferric form. Similarly, the addition of freshly synthesized microRNA $(10 \mu \mathrm{M}$ pri-miRNA added to $1.3 \mu \mathrm{M}$ DGCR8) did not induce any perturbation to either the DGCR8 ferric or the ferrous heme spectrum. This suggests that while the HBD (along with the dsRNA-binding domains) is predicted to be crucial for productive interactions with the primiRNAs, the substrate binding mode is not one that perturbs the heme ligation environment. ${ }^{32}$

EPR and Electron-Nuclear Double Resonance (ENDOR) Spectroscopy of DGCR8. Human DGCR8 in the ferric state gave rise to a rhombic EPR spectrum (Figure 2A) at $10 \mathrm{~K}$ with $g$ values of $2.61,2.27$, and 1.83 . Such spectra are typical of low-spin ferric $(S=1 / 2)$ hemes, and the $g$ values fall within the range previously associated with low-spin hemes having a thiolate proximal axial ligand. ${ }^{54} \mathrm{~A}$ similar EPR spectrum has been reported for DGCR8 from frog (Xenopus laevis). ${ }^{46}$

Davies pulsed ENDOR spectra recorded at a static field of $2650 \mathrm{G}, g=2.61$, revealed two groups of lines. The lines of one group are symmetrical about the ${ }^{1} \mathrm{H}$ Larmor frequency at this field, $11.3 \mathrm{MHz}$, and arise from hyperfine coupling to ${ }^{1} \mathrm{H}$ nuclei (protons) (Figure 2B). The central feature of this spectrum originates from unresolved hyperfine couplings to protons distant from the heme iron (matrix protons). ${ }^{55}$ A resolved hyperfine coupling of $5.1 \mathrm{MHz}$ is also evident. Spectra recorded using the same experimental parameters, but with a sample exchanged into $\mathrm{D}_{2} \mathrm{O}$ solvent, reveal that some of the matrix protons are exchangeable, with the largest ${ }^{1} \mathrm{H}$ hyperfine coupling to such an exchangeable proton being $2.4 \mathrm{MHz}$. Exchangeable protons attached to atoms directly ligating the heme in the distal position, such as water or substrate protons, typically have hyperfine couplings of $8-12 \mathrm{MHz},{ }^{56}$ protons of methylene groups $\beta$ to the ligating atom have been reported to exhibit hyperfine couplings of 5-7 MHz. ${ }^{57}$ The lines of the second group are found at lower frequencies, are not symmetrical about the ${ }^{1} \mathrm{H}$ Larmor frequency, and exhibit distinct differences in intensity. These lines arise from hyperfine coupling to ${ }^{14} \mathrm{~N}$ nuclei ${ }^{58}$ and are thus also subject to the effects of the ${ }^{14} \mathrm{~N}$ quadrupolar interaction with the frequencies of the lines, $\nu_{ \pm}$, being described by

$$
\nu_{ \pm}=\left|\nu_{\mathrm{N}} \pm A / 2 \pm 3 P / 2\right|
$$

where $\nu_{\mathrm{N}}$ is the ${ }^{14} \mathrm{~N}$ nuclear Larmor frequency, $0.81 \mathrm{MHz}, A$ is the hyperfine coupling, and $3 P$ is the quadrupole splitting. Taking lines of the same intensity as coming from the same spin manifold provides the assignment of those lines shown in 


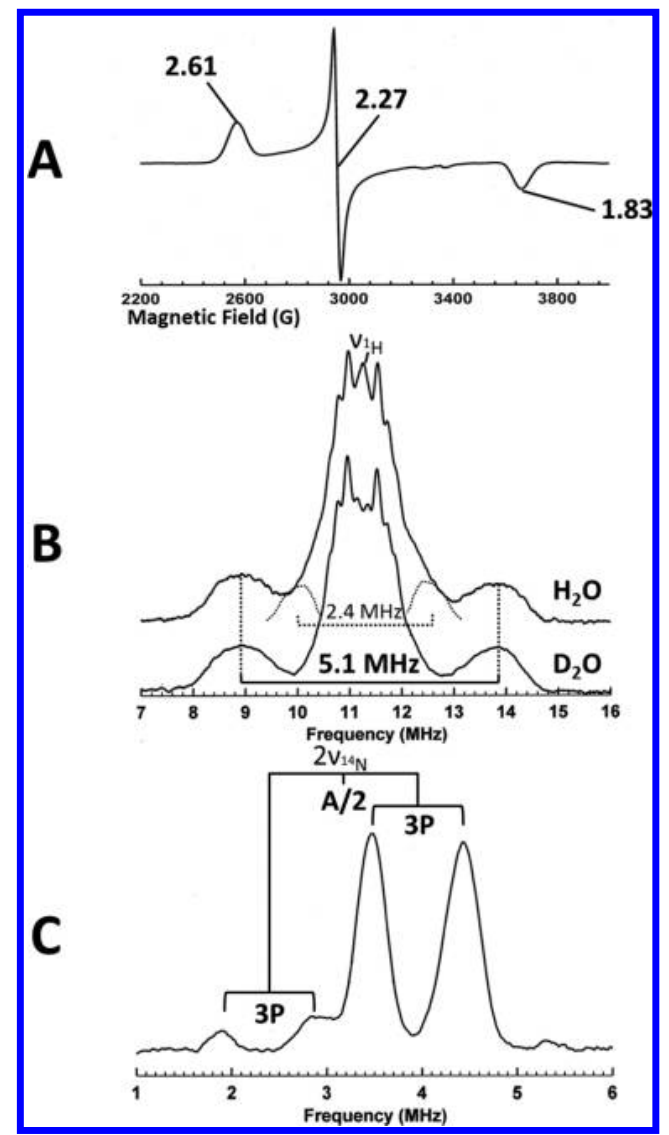

Figure 2. EPR and ENDOR spectroscopy of DGCR8. (A) X-Band continuous wave EPR spectrum of human DGCR8 recorded at $10 \mathrm{~K}$ with $g$ values marked. (B) X-Band Davies pulsed ENDOR spectra of human DGCR8 obtained at $10 \mathrm{~K}$ showing the region around the ${ }^{1} \mathrm{H}$ Larmor frequency. A resolved hyperfine coupling of $5.1 \mathrm{MHz}$ is marked together with the largest exchangeable proton hyperfine coupling of $2.4 \mathrm{MHz}$. (C) X-Band Davies pulsed ENDOR spectrum of human DGCR8 obtained at $10 \mathrm{~K}$ showing the low-frequency region. Analysis indicates a single ${ }^{14} \mathrm{~N}$ hyperfine coupling, and quadrupole splitting is shown.

Figure 2C. Only one hyperfine coupling of $6.3 \mathrm{MHz}$ and one quadrupolar interaction, with a quadrupolar splitting $3 P$ of 0.95 $\mathrm{MHz}$, are evident. Such values are typical for hyperfine coupling to the pyrrole nitrogens in low-spin ferric hemes with neutral distal ligands, because the quadrupolar splitting is sensitive to the presence of charged ligands, when observed along the normal to the heme plane. ${ }^{59}$ The small line widths evident in Figure 2C support such an orientation for the $g$ axis associated with the $g$ value of 2.61 . However, the detection of only one hyperfine coupling for all four pyrrole nitrogens is relatively unusual and suggests very high symmetry around the heme normal. ${ }^{60}$ Such symmetry has been observed for P450s with a thiolate proximal axial ligand and a neutral distal axial ligand, and in model compounds with two identical axial ligands. ${ }^{61}$ There is no evidence of hyperfine coupling to a ${ }^{14} \mathrm{~N}$ atom from an axial ligand.

Taken together, these ENDOR data exclude water and histidine as ligands to the heme iron due to the lack of a large hyperfine coupling to an exchangeable proton (or protons) and any ${ }^{14} \mathrm{~N}$ hyperfine coupling beyond that to the pyrrole nitrogens. The $0.95 \mathrm{MHz}$ quadrupole splitting suggests a neutral proximal ligand, such as a thiol (although ENDOR cannot distinguish between sulfur and oxygen without isotope labeling). However, the lack of a hyperfine coupling to an exchangeable proton large enough be attributed to the $-\mathrm{SH}$ group proton argues against this and suggests a thiolate distal axial ligand. The observation of a single ${ }^{14} \mathrm{~N}$ hyperfine coupling indicates an unusually high symmetry along the normal to the heme plane and therefore supports the latter model with two identical axial ligands. Thus, while the ENDOR data are equivocal, they provide the strongest support for bis-thiolate heme ligation in ferric DGCR8.

Resonance Raman Spectroscopy of DGCR8. Ferric DGCR8. The high-frequency region of the ferric DGCR8 sample is presented in Figure 3A. The region includes the oxidation-state and spin-state markers. The high-frequency spectrum of the DGCR8 sample exhibits the oxidation-state marker mode, $\nu_{4}$, at $1375 \mathrm{~cm}^{-1}$ and the $\nu_{3}$ spin-state marker at $1506 \mathrm{~cm}^{-1}$, confirming the presence of a ferric six-coordinate low-spin state, in agreement with results from other methods used in this study. While there are some small differences (3-6 $\mathrm{cm}^{-1}$ ) in frequencies between our results and those reported in the earlier published data of Barr et al., ${ }^{36}$ they can be attributed to the one-point spectral calibration method used in their work compared to the multipoint calibration used in our studies. Slight differences in relative intensities of bands between the two studies can be attributed to the fact that two different excitation lines were used $(441.6 \mathrm{~nm}$ in this study and $457.9 \mathrm{~nm}$ in the previous study). In the previous study, a weak $1471 \mathrm{~cm}^{-1}$ band was taken as evidence of a five-coordinate high-spin component. In our study, a band is also observed near this frequency $\left[1465 \mathrm{~cm}^{-1}\right.$ (Figure $\left.\left.3 \mathrm{~A}\right)\right]$ but is assigned to an internal mode of glycerol, whose concentration is $10 \%(\mathrm{v} / \mathrm{v})$ in our sample. The DGCR8 samples analyzed by Barr et al. also contained $10 \%$ glycerol. ${ }^{36}$ To verify the assignment of this 1465 $\mathrm{cm}^{-1}$ feature to glycerol, further experiments were conducted on a DGCR8 sample containing no glycerol. The inset in Figure 3A shows spectra of the ferric DGCR8 sample containing $10 \%$ glycerol buffer (a), a sample in the same buffer without glycerol (b), and their difference spectrum (c). In the difference spectrum, all the heme modes were cleanly canceled out, revealing only the $1465 \mathrm{~cm}^{-1}$ glycerol band. Thus, we assigned this band to the $10 \%$ glycerol present in the original protein solution, confirming the interpretation that the ferric protein samples studied here contain an insignificant amount of a five-coordinate high-spin (HS) state. The lowfrequency region of the RR spectrum is shown in Figure S1A.

Ferrous DGCR8. In the ferrous state, the high-frequency region (Figure $3 \mathrm{~B}$ ) exhibited the oxidation-state marker band $\left(\nu_{4}\right)$ at $1362 \mathrm{~cm}^{-1}$ and the spin-state marker band $\left(\nu_{3}\right)$ at 1495 $\mathrm{cm}^{-1}$, indicating a low-spin six-coordinated ferrous heme protein. Again, the weak broad glycerol band near $1465 \mathrm{~cm}^{-1}$ was observed. In the previous study, a $1470 \mathrm{~cm}^{-1}$ band was observed and assigned to the $\nu_{3}$ mode of a five-coordinate $\mathrm{HS}$ component, again prompting the conclusion of a mixture of five- and six-coordinate forms of the ferrous DGCR8, as was also reported in that work for DGCR8 in the ferric state. ${ }^{36}$ While that $1470 \mathrm{~cm}^{-1}$ feature is reasonably close to the expected glycerol band, the frequency observed is slightly higher than expected. Considering it not to be a miscalibrated glycerol band, the authors assigned it to the $\nu_{3}$ mode of a HS component, also assigning a feature at $1579 \mathrm{~cm}^{-1}$ to the $\nu_{2}$ mode of that HS component. However, this frequency is unusually high for a HS component. Assuming that the 1470 $\mathrm{cm}^{-1}$ feature observed by Barr et al. does provide confirmation of a HS component, this would suggest that the sample studied 


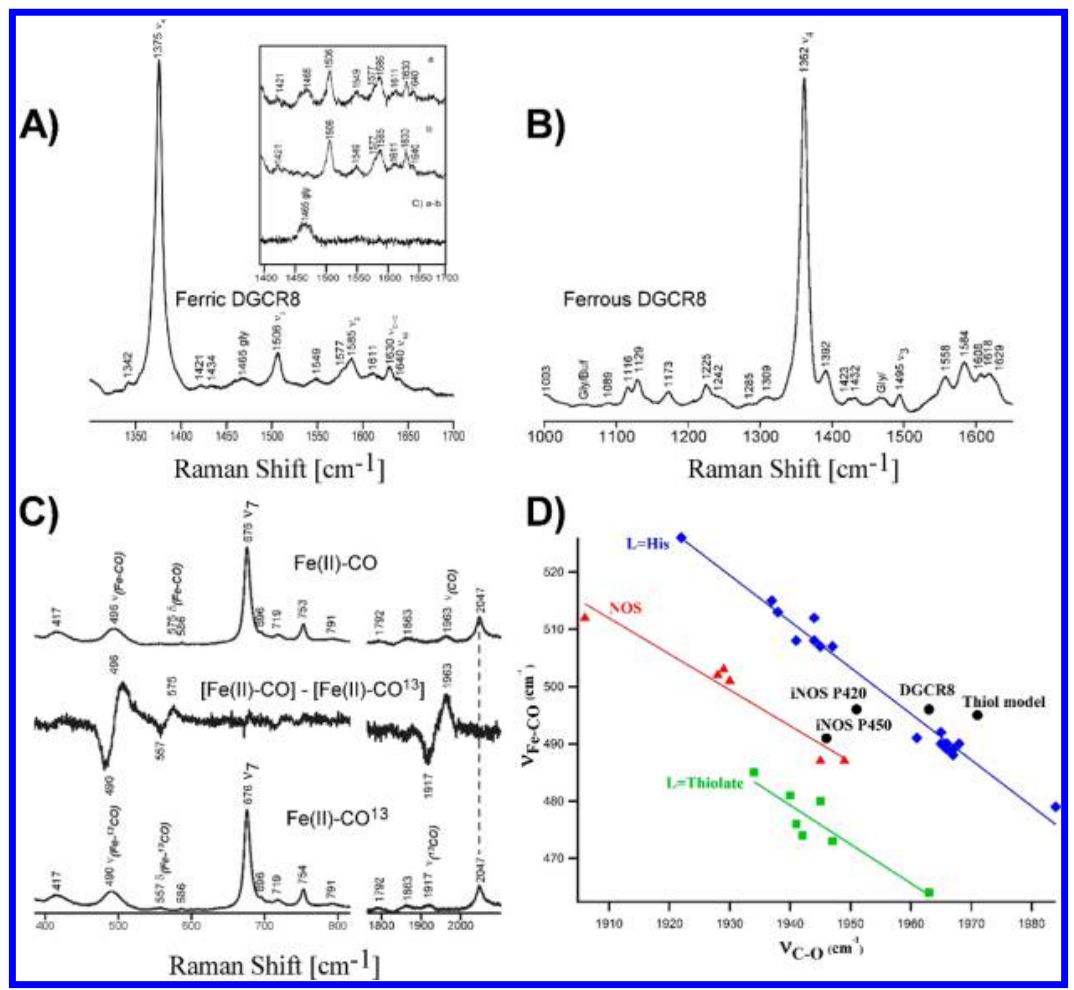

Figure 3. Resonance Raman spectroscopy of DGCR8. (A) High-frequency RR spectrum of the ferric DGCR8 acquired with a $441.6 \mathrm{~nm}$ laser line [ $85 \mu \mathrm{M}$ ferric DGCR8, in $50 \mathrm{mM}$ Tris (pH 8.0) containing $500 \mathrm{mM} \mathrm{KCl}$ and $10 \%$ glycerol]. The inset shows the region from $\sim 1390 \mathrm{~cm}^{-1}$ upward for the ferric DGCR8 in 10\% glycerol buffer (a), ferric DGCR8 in the same buffer without glycerol (b), and their difference trace (c). (B) Highfrequency RR spectrum of the ferrous DGCR8 acquired with a $415 \mathrm{~nm}$ laser line (85 $\mu \mathrm{M}$ DGCR8 reduced under an inert atmosphere of $\mathrm{N}_{2}$ with a 20 -fold molar excess of sodium dithionite in the presence of methyl viologen and benzyl viologen). (C) Low-frequency (left side of each spectrum) and high-frequency (right side of each spectrum) RR spectral region of the ferrous-CO adducts of DGCR8. The top traces show the RR spectra of the $\mathrm{Fe}^{\mathrm{II}}-{ }^{12} \mathrm{CO}$ adduct, whereas the bottom traces show those of the $\mathrm{Fe} \mathrm{II}^{\mathrm{II}}{ }^{13} \mathrm{CO}$ adduct. The traces in the central panels show the ${ }^{12} \mathrm{CO}$ minus ${ }^{13} \mathrm{CO}$ difference plots in the $\nu_{(\mathrm{Fe}-\mathrm{C})}$ and $\nu_{(\mathrm{C}-\mathrm{O})}$ regions, respectively. (D) CO backbonding correlation lines of P450cam (L $=$ thiolate), histidine-ligated enzymes $(\mathrm{L}=\mathrm{His})$, and NOS $\left(\mathrm{L}=\right.$ thiolate). ${ }^{78}$ Data points are associated with a heme-thiol model complex, DGCR8 (this study), and iNOS P420 and iNOS P450 forms. ${ }^{67}$

previously (frog DGCR8, amino acids 278-498) does form a HS component, while the isoform studied here (human DGCR8, amino acids 276-773) does not form a HS species under our conditions. The low-frequency RR spectrum of ferrous DGCR8 is shown in Figure S1B.

Ferrous-CO Complex of DGCR8. As discussed above, the appearance of a Soret band near $420 \mathrm{~nm}$ for the ferrous CO adduct of DGCR8 is indicative of a six-coordinate CO-ligated heme bearing a neutral (e.g., thiol or histidine) trans-axial ligand. Resonance Raman spectra in the region between 1000 and $1650 \mathrm{~cm}^{-1}$, provided in Figure S1D, reveal the oxidationstate marker band $\left(\nu_{4}\right)$ at $1373 \mathrm{~cm}^{-1}$ and the spin-state marker band $\left(\nu_{3}\right)$ at $1497 \mathrm{~cm}^{-1}$, consistent with values typically seen for these low-spin $\mathrm{CO}$ adducts of cytochromes P450. ${ }^{62,63}$ The regions of the $\mathrm{RR}$ spectra of the $\mathrm{Fe}^{\mathrm{II}}-\mathrm{CO}$ and $\mathrm{Fe}^{\mathrm{II}}-{ }^{13} \mathrm{CO}$ adducts of DGCR8, wherein the $\nu(\mathrm{Fe}-\mathrm{C})$ and $\nu(\mathrm{C}-\mathrm{O})$ stretching modes occur, are shown in Figure 3C. In the lowerfrequency region, a clean difference pattern emerges from a $\nu\left(\mathrm{Fe}-{ }^{12} \mathrm{C}\right)$ mode appearing at $496 \mathrm{~cm}^{-1}$, with its ${ }^{13} \mathrm{C}$ counterpart shifting to $490 \mathrm{~cm}^{-1}$. The corresponding $\nu(\mathrm{C}-$ O) bands appear at $1963 \mathrm{~cm}^{-1}$ for ${ }^{12} \mathrm{C}-\mathrm{O}$ and at $1917 \mathrm{~cm}^{-1}$ for the ${ }^{13} \mathrm{C}$ analogue. Finally, a clean difference pattern, with components at 575 and $557 \mathrm{~cm}^{-1}$, reveals the $\delta(\mathrm{Fe}-\mathrm{C}-\mathrm{O})$ bending mode.

Figure $3 \mathrm{D}$ shows the well-established inverse correlation plots for $\nu(\mathrm{Fe}-\mathrm{C})$ versus $\nu(\mathrm{C}-\mathrm{O})$ modes, which are useful for probing the nature of the distal heme pockets and proximal ligands. ${ }^{64}$ Thus, the lowest line in the figure includes data for the cytochromes $\mathrm{P} 450$, which possess a strongly electron donating thiolate proximal ligand, leading to relatively high $\nu(\mathrm{Fe}-\mathrm{S})$ stretching modes occurring near $350-355 \mathrm{~cm}^{-1}$. Just above this line lies the correlation plot for NOS enzymes; possessing lower $\nu(\mathrm{Fe}-\mathrm{S})$ frequencies $\left(337-343 \mathrm{~cm}^{-1}\right)$, these show correspondingly higher $\nu(\mathrm{Fe}-\mathrm{C})$ stretching modes. At the highest point in the figure is the correlation line for histidine-bound $\mathrm{Fe}^{\mathrm{II}}-\mathrm{CO}$ complexes. As discussed above, protonation of the trans-axial thiolate to form a trans-thiolligated species, as suggested for cytochromes P420, ${ }^{65}$ would lead to an even weaker $\mathrm{Fe}-\mathrm{S}$ bond and higher $\nu(\mathrm{Fe}-\mathrm{C})$ stretching frequencies, compared to those seen for NOS adducts. Indeed, the points acquired for the P420 forms of iNOS and for CYP101A1 (the camphor hydroxylase $\mathrm{P} 450 \mathrm{cam}),{ }^{66}$ as well as one for a well-characterized $\mathrm{CO}$ adduct of a heme model compound bearing a trans-axial thiol, ${ }^{67}$ lie near the line corresponding to histidine-ligated $\mathrm{CO}$ adducts. The point determined herein for the CO adduct of DGCR8 clearly lies in the neighborhood of those adducts bearing a trans-axial thiol ligand, a result that is consistent with the conclusion that the ferrous form of the enzyme possesses a thiol/thiol coordination environment.

Magnetic Circular Dichroism (MCD) Spectroscopy of DGCR8. The continuous wave (CW) EPR spectrum of $\Delta 276$ DGCR8 contains sharp features with principal $g$ values of 2.61, 2.27 , and 1.83, confirming that the ferric heme iron is almost 


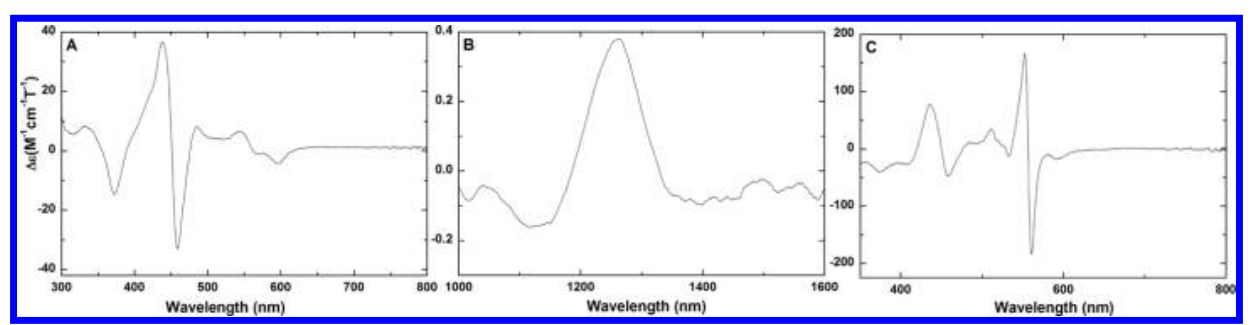

Figure 4. UV-vis and near-infrared MCD spectra of DGCR8. (A) UV-vis MCD spectrum of ferric DGCR8 (70 $\mu \mathrm{M})$, with a derivative at $451 \mathrm{~nm}$ and a strong negative feature at $597 \mathrm{~nm}$. (B) Near-infrared MCD spectrum of ferric DGCR8 $(70 \mu \mathrm{M})$ with a strong band at $1260 \mathrm{~nm}$ reporting on the coordination state of the heme iron. (C) UV-vis MCD spectrum of the ferrous form of DGCR8 (185 $\mu \mathrm{M})$, with a feature at $436 \mathrm{~nm}$ and a derivative at $556 \mathrm{~nm}$.

exclusively in the low-spin state. For b-type cytochromes, such a spectrum is diagnostic of axial ligation by thiolate. To provide further insights into the nature of the second axial ligand to the DGCR8 heme iron, we used MCD as a complementary spectroscopic method. ${ }^{54}$

Figure 4 shows MCD spectra of ferric DGCR8 in UV-vis and near-infrared (NIR) regions and for ferrous DGCR8 in the $\mathrm{UV}-$ vis region. Figure 4A shows the UV-vis MCD spectrum of ferric DGCR8 with a Soret derivative at $451 \mathrm{~nm}$ and a Qband region derivative at $556 \mathrm{~nm}$. NIR MCD spectroscopy of low-spin ferric heme affords a direct measurement of the porphyrin-to-iron LMCT (ligand-to-metal charge transfer) transition, and this is often sufficient to allow unambiguous assignment of axial ligation. ${ }^{68}$ Figure $4 \mathrm{~B}$ shows the NIR MCD spectrum of ferric DGCR8. The charge transfer band in the NIR region is located at $1260 \mathrm{~nm}$, outside the range reported for heme with $\mathrm{Cys}^{-} / \mathrm{H}_{2} \mathrm{O}$ or $\mathrm{Cys}^{-} / \mathrm{His}$ as axial ligands (1050$1200 \mathrm{~nm}) .{ }^{69-71}$ This observation, together with the assignment of $\mathrm{Cys}^{-}$ligation based on the CW EPR, suggests an unusual trans-axial ligand to the DGCR8 ferric heme iron. On the basis of conclusions from other spectroscopic analyses reported here, we would favor cysteine thiolate as the trans-axial ligand. However, a trans-thiol ligand might also be possible. In favor of the assignment of bis-thiolate coordination in ferric DGCR8, the UV-vis MCD spectrum of DGCR8 contains an unusual negative band at $597 \mathrm{~nm}$, in addition to the derivative features at 451 and $556 \mathrm{~nm}$ typical of ferric heme. A highly similar UVvis $\mathrm{MCD}$ spectrum is seen for the cysteine thiolate-coordinated, ferric heme iron form of the Caldariomyces fumago chloroperoxidase (CPO) in complex with methanethiol. ${ }^{72} \mathrm{UV}-$ vis absorbance analysis of the $\mathrm{CPO}-$ methanethiol complex shows a clear hyperporphyrin spectrum, consistent with bisthiolate heme ligation. ${ }^{72}$ Thus, we conclude from these MCD studies that the heme of DGCR8 is indeed ligated by two cysteine residues in the ferric state, with both these residues in their thiolate form.

In contrast to the readily observed NIR MCD bands of lowspin ferric hemes, the corresponding LMCT transitions for ferrous hemes are symmetry-forbidden, precluding ligand assignment for reduced hemes on this basis. However, the form of the UV-vis MCD in the reduced state can be used to confirm ligation by cysteinate, as this gives an abnormally low intensity $\alpha, \beta$ band with a peak-to-trough intensity of $\sim 70 \mathrm{M}^{-1}$ $\mathrm{cm}^{-1} \mathrm{~T}^{-1} \cdot{ }^{73} \mathrm{UV}-$ vis MCD spectra of reduced DGCR8 were recorded (Figure 4C). Sodium dithionite reductant was added to the sample under anaerobic conditions, and UV-vis absorbance and MCD spectra were recorded after $4 \mathrm{~h}$ at 20 ${ }^{\circ} \mathrm{C}$. Following data collection, it became apparent that a small proportion of the enzyme had reoxidized $(\sim 15 \%)$. To account for the partial reoxidation, the spectra were corrected by removal of the small spectral contribution from the ferric enzyme (with reference to the UV-vis absorption and MCD spectra of the ferric DGCR8) to produce the ferrous DGCR8 spectra without a significant contribution from the ferric species. The calculated UV-vis MCD spectrum of reduced DGCR8 (Figure 4C) has a much greater intensity in this region, approximately $350 \mathrm{M}^{-1} \mathrm{~cm}^{-1} \mathrm{~T}^{-1}$. Furthermore, this band is located at $556 \mathrm{~nm}$ with the maximal Soret intensity at $436 \mathrm{~nm}$, in contrast with the 550 and $416 \mathrm{~nm}$ bands, respectively, observed for SoxAX, an enzyme that couples disulfide bond formation to cytochrome $c$ reduction in a widespread microbial sulfur oxidation pathway and has the more common $\mathrm{Cys}^{-} / \mathrm{His}$ ligand set. ${ }^{73}$ Both the intensity and the position of the UV-vis MCD bands of reduced DGCR8 are far more similar to those of the reduced form of a model complex with bis-thiol ligation $\left(\alpha, \beta\right.$ intensity of $220 \mathrm{M}^{-1} \mathrm{~cm}^{-1}$ $\mathrm{T}^{-1}$ at $555 \mathrm{~nm}$, Soret band at $\left.>430 \mathrm{~nm}\right) .{ }^{48}$ Thus, while the form of the MCD spectrum does not preclude displacement of $\mathrm{Cys}^{-}$ by a neutral ligand (such as His-imidazole) upon reduction, it is also consistent with protonation of this residue resulting in a $\mathrm{CysH} / \mathrm{CysH}$-coordinated ferrous heme.

\section{CONCLUSIONS}

DGCR8 is an unusual hemoprotein with spectroscopic features distinct from those of other heme $b$-binding proteins. Binding of heme to the DGCR8 dimer stabilizes the protein, and the DGCR8 dimer forms a complex with the RNase Drosha that is crucial for pri-miRNA processing. ${ }^{46,74,75}$ Our combined spectroscopic studies identify axial coordination of DGCR8 by two sulfur-containing amino acids in both its ferric and ferrous states. Data are consistent with $\mathrm{Cys}^{-} / \mathrm{Cys}^{-}$(bisthiolate) axial coordination of the ferric DGCR8 heme $b$, but indicate that ferrous DGCR8 likely adopts $\mathrm{CysH} / \mathrm{CysH}$ (bisthiol) ligation. Addition of the pri-miRNA substrate to the (active) ferric DGCR8 form does not perturb its heme spectrum, suggesting that the pri-miRNA-binding site does not overlap the heme site, even though recent studies indicate that portions of the HBD are crucial for interactions with primiRNA. ${ }^{32}$

The rhombic EPR spectrum of low-spin ferric DGCR8 indicates a single dominant axial ligation mode (Figure 2A). Cys352 was proposed as an axial ligand to the heme iron, and modeling suggests that Cys352 thiolates from two monomers of the HBD act as axial ligands to a hexacoordinated DGCR8 heme iron at the dimer interface. ${ }^{36}$ Spectroscopic analyses presented in this paper are consistent with bis-Cys coordination of DGCR8 heme iron. In particular, our ENDOR data for ferric DGCR8 confirm a highly symmetrical heme coordination environment and rule out water or histidine as axial ligands, 
instead favoring a $\mathrm{Cys}^{-} / \mathrm{Cys}^{-}$axial ligand pair. The $\Delta 276$ DGCR8 hemoprotein is reduced by dithionite to produce a species with a Soret band shift to $427 \mathrm{~nm}$, similar to that for the reduced frog DGCR8 HBD form. However, the absorption coefficient reported for the ferrous frog HBD $\left(\varepsilon_{424}=55 \mathrm{mM}^{-1}\right.$ $\left.\mathrm{cm}^{-1}\right)$ is much lower than that we report here for ferrous human DGCR8. ${ }^{36}$ The Soret coefficient is $\varepsilon_{450}=70 \mathrm{mM}^{-1}$ $\mathrm{cm}^{-1}$ for ferric human DGCR8, while that for the ferrous DGCR8 is considerably higher $\left(\varepsilon_{427}=112 \mathrm{mM}^{-1} \mathrm{~cm}^{-1}\right)$. The DGCR8 ferrous-CO complex has an even more intense Soret feature $\left(\varepsilon_{421}=168 \mathrm{mM}^{-1} \mathrm{~cm}^{-1}\right)$ (Figure 1A). The absorption coefficient for the P420 ferrous-CO (thiol-coordinated) form of cytochrome P450 enzymes is also larger than that for the P450 (thiolate-coordinated) form, consistent with the presence of a cysteine thiol ligand trans to the CO in the DGCR8 complex. $^{76}$

Barr et al. concluded that the ferrous frog HBD does not have cysteine thiolate coordination. This is consistent with our data that indicate ferrous human DGCR8 has $\mathrm{CysH} / \mathrm{CysH}$ coordination. However, their conclusion that multiple spin and/or heme iron coordination states are present is not supported by our ferrous DGCR8 spectroscopic data. Barr et al. reported spectra of the human NC1 form of DGCR8 reduced by $2 \mathrm{mM}$ dithionite at $\mathrm{pH} 6.0$. However, the heme spectrum appears to be extensively bleached with substantial contributions from dithionite and is devoid of any clear Soret feature at $\sim 427 \mathrm{~nm}^{36}$ These data are in marked contrast to our UV-vis data for human DGCR8, where well-defined ferrous (and Fe ${ }^{\mathrm{II}}$ CO) spectra are observed. We attempted to determine the human DGCR8 redox potential using spectroelectrochemistry, as described previously. ${ }^{52,77}$ Aggregation of DGCR8 occurred over the course of the experiment, preventing accurate estimation of the midpoint potential for the heme $\mathrm{Fe}^{\mathrm{III}} / \mathrm{Fe}^{\mathrm{II}}$ couple. However, the data clearly showed that the DGCR8 heme iron potential is lower than $-350 \mathrm{mV}$ versus NHE. This suggests that ferric DGCR8 predominates under cellular conditions, consistent with ferric DGCR8 being the active species in pri-miRNA processing. ${ }^{36}$

Our UV-vis MCD spectrum of ferric human DGCR8 displays features similar to those of the spectrum of frog DGCR8 HBD but provides sharper resolution of bands, particularly in the $\alpha / \beta$ (Q) band and LMCT regions (Figure $4 \mathrm{~A}){ }^{46}$ This permits identification of an unusual negative band at $597 \mathrm{~nm}$, and its assignment to bis-cysteine thiolate ferric heme iron coordination by comparison to a highly similar spectrum of the methanethiol complex of CPO, and with reference to the nearly complete hyperporphyrin UV-vis spectrum of the same complex. ${ }^{72}$ We also present the first MCD data for a ferric DGCR8 protein in the NIR region and for ferrous DGCR8 in the UV-vis region. From the ferric NIR data set, the novel $\mathrm{Cys}^{-} / \mathrm{Cys}^{-}$assignment is associated with the unusual position of the MCD NIR CT band at $1260 \mathrm{~nm}$. The well-defined ferrous DGCR8 UV-vis MCD spectrum has intensity much greater than that of the ferric DGCR8 spectrum and resembles that of a bis-thiol-coordinated model complex. ${ }^{48}$ This observation, along with RR data for $\mathrm{Fe}^{\mathrm{II}}-\mathrm{CO}$ DGCR8, is consistent with $\mathrm{CysH} / \mathrm{CysH}$ coordination of ferrous DGCR8, as opposed to displacement of the axial ligand(s) or their replacement with undefined ligands, as suggested previously. ${ }^{36}$

In conclusion, we present detailed analyses of heme binding in the pre-miRNA processing protein DGCR8. Assignments of heme coordination are made from spectroscopic studies of human DGCR8 in both ferric and ferrous states. Contrary to previous work, ${ }^{36}$ we assign the axial ligands as $\mathrm{Cys}^{-} / \mathrm{Cys}^{-}$in active, ferric DGCR8 and as CysH/CysH in ferrous DGCR8, with Cys352 residues from each monomer of a HBD domain dimer providing the sulfur thiolate or thiol axial ligands.

\section{ASSOCIATED CONTENT}

\section{S Supporting Information}

The Supporting Information is available free of charge on the ACS Publications website at DOI: 10.1021/acs.biochem.6b00204.

Additional resonance Raman (RR) spectra of the ferric, ferrous, and ferrous-CO forms of the human DGCR8 protein $(\mathrm{PDF})$

\section{AUTHOR INFORMATION}

\section{Corresponding Author}

*Centre for Synthetic Biology of Fine and Specialty Chemicals (SYNBIOCHEM), Manchester Institute of Biotechnology, Faculty of Life Sciences, University of Manchester, 131 Princess St., Manchester M1 7DN, U.K. Phone: 0044-161-306-5151. Email: Andrew.Munro@Manchester.ac.uk.

\section{Funding}

This research was supported by funding from the UK Biotechnology and Biological Sciences Research Council (BBSRC Grant BB/F014252/1) to A.W.M. and by a grant from the National Science Foundation (MCB 0951115) to J.R.K.

\section{Notes}

The authors declare no competing financial interest.

\section{ACKNOWLEDGMENTS}

The authors acknowledge Dr. Mark Dunstan (University of Manchester) for assistance in RNA preparation and Mrs. Marina Golovanova (University of Manchester) for assistance with protein expression.

\section{ABBREVIATIONS}

DGCR8, DiGeorge critical region 8 protein; ENDOR, electron-nuclear double resonance; EPR, electron paramagnetic resonance; MCD, magnetic circular dichroism; miRISC, miRNA-induced silencing complex; miRNA, microRNA; NIR, near-infrared; pre-miRNA, precursor miRNA; primiRNA, primary miRNA; UTR, untranslated region; UV-vis, ultraviolet-visible.

\section{REFERENCES}

(1) Krol, J., Loedige, I., and Filipowicz, W. (2010) The widespread regulation of microRNA biogenesis, function and decay. Nat. Rev. Genet. 11, 597-610.

(2) Llave, C., Xie, Z. X., Kasschau, K. D., and Carrington, J. C. (2002) Cleavage of Scarecrow-like mRNA targets directed by a class of Arabidopsis miRNA. Science 297, 2053-2056.

(3) Olsen, P. H., and Ambros, V. (1999) The lin-4 regulatory RNA controls developmental timing in Caenorhabditis elegans by blocking LIN-14 protein synthesis after the initiation of translation. Dev. Biol. 216, 671-680.

(4) Yekta, S., Shih, I. H., and Bartel, D. P. (2004) MicroRNAdirected cleavage of HOXB8 mRNA. Science 304, 594-596.

(5) Zeng, Y., Wagner, E. J., and Cullen, B. R. (2002) Both natural and designed micro RNAs technique can inhibit the expression of cognate mRNAs when expressed in human cells. Mol. Cell 9, 1327-1333. 
(6) Cai, X. Z., Hagedorn, C. H., and Cullen, B. R. (2004) Human microRNAs are processed from capped, polyadenylated transcripts that can also function as mRNAs. RNA 10, 1957-1966.

(7) Lee, Y., Kim, M., Han, J. J., Yeom, K. H., Lee, S., Baek, S. H., and Kim, V. N. (2004) MicroRNA genes are transcribed by RNA polymerase II. EMBO I. 23, 4051-4060.

(8) Zeng, Y., and Cullen, B. R. (2005) Efficient processing of primary microRNA hairpins by drosha requires flanking nonstructured RNA sequences. I. Biol. Chem. 280, 27595-27603.

(9) Lee, Y., Jeon, K., Lee, J. T., Kim, S., and Kim, V. N. (2002) MicroRNA maturation: stepwise processing and subcellular localization. EMBO I. 21, 4663-4670.

(10) Lund, E., Guttinger, S., Calado, A., Dahlberg, J. E., and Kutay, U. (2004) Nuclear export of microRNA precursors. Science 303, 95-98.

(11) Lee, Y., Ahn, C., Han, J. J., Choi, H., Kim, J., Yim, J., Lee, J., Provost, P., Radmark, O., Kim, S., and Kim, V. N. (2003) The nuclear RNase III Drosha initiates microRNA processing. Nature 425, 415419.

(12) Denli, A. M., Tops, B. B. J., Plasterk, R. H. A., Ketting, R. F., and Hannon, G. J. (2004) Processing of primary microRNAs by the Microprocessor complex. Nature 432, 231-235.

(13) Gregory, R. I., Yan, K. P., Amuthan, G., Chendrimada, T., Doratotaj, B., Cooch, N., and Shiekhattar, R. (2004) The Microprocessor complex mediates the genesis of microRNAs. Nature 432, 235-240.

(14) Han, J. J., Lee, Y., Yeom, K. H., Kim, Y. K., Jin, H., and Kim, V. N. (2004) The Drosha-DGCR8 complex in primary microRNA processing. Genes Dev. 18, 3016-3027.

(15) Landthaler, M., Yalcin, A., and Tuschl, T. (2004) The human DiGeorge syndrome critical region gene 8 and its D-melanogaster homolog are required for miRNA biogenesis. Curr. Biol. 14, 21622167.

(16) Bernstein, E., Caudy, A. A., Hammond, S. M., and Hannon, G. J. (2001) Role for a bidentate ribonuclease in the initiation step of RNA interference. Nature 409, 363-366.

(17) Hutvagner, G., McLachlan, J., Pasquinelli, A. E., Balint, E., Tuschl, T., and Zamore, P. D. (2001) A cellular function for the RNAinterference enzyme Dicer in the maturation of the let-7 small temporal RNA. Science 293, 834-838.

(18) Ketting, R. F., Fischer, S. E. J., Bernstein, E., Sijen, T., Hannon, G. J., and Plasterk, R. H. A. (2001) Dicer functions in RNA interference and in synthesis of small RNA involved in developmental timing in C-elegans. Genes Dev. 15, 2654-2659.

(19) Khvorova, A., Reynolds, A., and Jayasena, S. D. (2003) Functional siRNAs and rniRNAs exhibit strand bias. Cell 115, 209216.

(20) Schwarz, D. S., Hutvagner, G., Du, T., Xu, Z. S., Aronin, N., and Zamore, P. D. (2003) Asymmetry in the assembly of the RNAi enzyme complex. Cell 115, 199-208.

(21) Czech, B., Zhou, R., Erlich, Y., Brennecke, J., Binari, R., Villalta, C., Gordon, A., Perrimon, N., and Hannon, G. J. (2009) Hierarchical rules for Argonaute loading in Drosophila. Mol. Cell 36, 445-456.

(22) Ghildiyal, M., Xu, J., Seitz, H., Weng, Z., and Zamore, P. D. (2010) Sorting of Drosophila small silencing RNAs partitions microRNA* strands into the RNA interference pathway. RNA 16, $43-56$.

(23) Okamura, K., Liu, N., and Lai, E. C. (2009) Distinct mechanisms for microRNA strand selection by Drosophila Argonautes. Mol. Cell 36, 431-444.

(24) Yang, J. S., and Lai, E. C. (2011) Alternative miRNA Biogenesis Pathways and the Interpretation of Core miRNA Pathway Mutants. Mol. Cell 43, 892-903.

(25) Sohn, S. Y., Bae, W. J., Kim, J. J., Yeom, K.-H., Kim, V. N., and Cho, Y. (2007) Crystal structure of human DGCR8 core. Nat. Struct. Mol. Biol. 14, 847-853.

(26) Faller, M., Matsunaga, M., Yin, S., Loo, J. A., and Guo, F. (2007) Heme is involved in microRNA processing. Nat. Struct. Mol. Biol. 14, 23-29.
(27) Senturia, R., Faller, M., Yin, S., Loo, J. A., Cascio, D., Sawaya, M. R, Hwang, D., Clubb, R. T., and Guo, F. (2010) Structure of the dimerization domain of DiGeorge Critical Region 8. Protein Sci. 19, 1354-1365.

(28) Yeom, K. H., Lee, Y., Han, J. J., Suh, M. R., and Kim, V. N. (2006) Characterization of DGCR8/Pasha, the essential cofactor for Drosha in primary miRNA processing. Nucleic Acids Res. 34, 46224629.

(29) Pickering, B. F., Yu, D. H., and Van Dyke, M. W. (2011) Nucleolin protein interacts with Microprocessor complex to affect biogenesis of microRNAs 15a and 16. L. Biol. Chem. 286, 4409544103.

(30) Suzuki, H. I., Yamagata, K., Sugimoto, K., Iwamoto, T., Kato, S., and Miyazono, K. (2009) Modulation of microRNA processing by p53. Nature 460, 529-U111.

(31) Weitz, S. H., Gong, M., Barr, I., Weiss, S., and Guo, F. (2014) Processing of microRNA primary transcripts requires heme in mammalian cells. Proc. Natl. Acad. Sci. U. S. A. 111, 1861-1866.

(32) Quick-Cleveland, J., Jacob, J. P., Weitz, S. H., Shoffner, G., Senturia, R., and Guo, F. (2014) The DGCR8 RNA-binding heme domain recognizes primary microRNAs by clamping the hairpin. Cell Rep. 7, 1994-2005.

(33) Munro, A. W., Girvan, H. M., Mason, A. E., Dunford, A. J., and McLean, K. J. (2013) What makes a P450 tick? Trends Biochem. Sci. 38, $140-150$.

(34) Girvan, H. M., and Munro, A. W. (2013) Heme sensor proteins. I. Biol. Chem. 288, 13194-13203.

(35) Roberts, G. P., Thorsteinsson, M. V., Kerby, R. L., Lanzilotta, W. N., and Poulos, T. (2001) CooA: a heme-containing regulatory protein that serves as a specific sensor of both carbon monoxide and redox state. Prog. Nucleic Acid Res. Mol. Biol. 67, 35-63.

(36) Barr, I., Smith, A. T., Chen, Y. Q., Senturia, R., Burstyn, J. N., and Guo, F. (2012) Ferric, not ferrous, heme activates RNA-binding protein DGCR8 for primary microRNA processing. Proc. Natl. Acad. Sci. U. S. A. 109, 1919-1924.

(37) Kozomara, A., and Griffiths-Jones, S. (2011) miRBase: integrating microRNA annotation and deep-sequencing data. Nucleic Acids Res. 39, D152-D157.

(38) Walker, S. C., Avis, J. M., and Conn, G. L. (2003) General plasmids for producing RNA in vitro transcripts with homogeneous ends. Nucleic Acids Res. 31, e82.

(39) Gurevich, V. V. (1996) Use of bacteriophage RNA polymerase in RNA synthesis. In Viral Polvmerases and Related Proteins, pp 382397, Academic Press Inc., San Diego.

(40) Sambrook, J., and Russell, D. W. (2001) Molecular Cloning: A Laboratory Manual, 3rd ed., Cold Spring Harbor Laboratory Press, Plainview, NY.

(41) Berry, E. A., and Trumpower, B. L. (1987) Simultaneous determination of hemes-a, hemes- $\mathrm{B}$, and hemes- $\mathrm{C}$ from pyridine hemochrome spectra. Anal. Biochem. 161, 1-15.

(42) Davies, E. R. (1974) New pulse ENDOR technique. Phvs. Lett. A 47, 1-2.

(43) Sono, M., Andersson, L. A., and Dawson, J. H. (1982) Sulfur donor ligand-binding to ferric cytochrome-P-450-cam and myoglobin. Ultraviolet-visible absorption, magnetic circular dichroism, and electron-paramagnetic resonance spectroscopy investigation of the complexes. I. Biol. Chem. 257, 8308-8320.

(44) Ullrich, V., Nastainczyk, W., and Ruf, H. H. (1975) Ligand reactions of cytochrome P-450. Biochem. Soc. Trans. 3, 803-807.

(45) Bui, S. H., McLean, K. J., Cheesman, M. R., Bradley, J. M., Rigby, S. E., Levy, C. W., Leys, D., and Munro, A. W. (2012) Unusual spectroscopic and ligand binding properties of the cytochrome P450flavodoxin fusion enzyme XplA. I. Biol. Chem. 287, 19699-19714.

(46) Barr, I., Smith, A. T., Senturia, R., Chen, Y. Q., Scheidemantle, B. D., Burstyn, J. N., and Guo, F. (2011) DiGeorge critical region 8 (DGCR8) is a double-cysteine-ligated heme protein. L. Biol. Chem. 286, 16716-16725.

(47) Senturia, R., Laganowsky, A., Barr, I., Scheidemantle, B. D., and Guo, F. (2012) Dimerization and heme binding are conserved in 
amphibian and starfish homologues of the microRNA processing protein DGCR8. PLoS One 7, e39688.

(48) Perera, R., Sono, M., Sigman, J. A., Pfister, T. D., Lu, Y., and Dawson, J. H. (2003) Neutral thiol as a proximal ligand to ferrous heme iron: Implications for heme proteins that lose cysteine thiolate ligation on reduction. Proc. Natl. Acad. Sci. U. S. A. 100, 3641-3646.

(49) Du, J., Sono, M., and Dawson, J. H. (2011) The H93G myoglobin cavity mutant as a versatile scaffold for modeling heme iron coordination structures in protein active sites and their characterization with magnetic circular dichroism spectroscopy. Coord. Chem. Rev. 255, 700-716.

(50) Aoyama, Y., Horiuchi, T., Gotoh, O., Noshiro, M., and Yoshida, Y. (1998) CYP51-like gene of Mycobacterium tuberculosis actually encodes a P450 similar to eukaryotic CYP51. L. Biochem. 124, 694696.

(51) Dunford, A. J., McLean, K. J., Sabri, M., Seward, H. E., Heyes, D. J., Scrutton, N. S., and Munro, A. W. (2007) Rapid P450 heme iron reduction by laser photoexcitation of Mycobacterium tuberculosis CYP121 and CYP51B1 - Analysis of CO complexation reactions and reversibility of the P450/P420 equilibrium. I. Biol. Chem. 282, 2481624824.

(52) McLean, K. J., Warman, A. J., Seward, H. E., Marshall, K. R., Girvan, H. M., Cheesman, M. R., Waterman, M. R., and Munro, A. W. (2006) Biophysical characterization of the sterol demethylase P450 from Mycobacterium tuberculosis, its cognate ferredoxin, and their interactions. Biochemistry 45, 8427-8443.

(53) Sun, Y. H., Zeng, W. Q., Benabbas, A., Ye, X., Denisov, I., Sligar, S. G., Du, J., Dawson, J. H., and Champion, P. M. (2013) Investigations of heme ligation and ligand switching in cytochromes P450 and P420. Biochemistry 52, 5941-5951.

(54) Dawson, J. H., Andersson, L. A., and Sono, M. (1982) Spectroscopic investigations of ferric cytochrome P-450cam ligand complexes - Identification of the ligand trans to cysteine in the native enzyme. L. Biol. Chem. 257, 3606-3617.

(55) Hyde, J. S., Rist, G. H., and Eriksson, L. E. (1968) Endor of methyl, matrix, and $\alpha$ protons in amorphous and polycrystalline matrices. I. Phvs. Chem. 72, 4269-4276.

(56) Lobrutto, R., Scholes, C. P., Wagner, G. C., Gunsalus, I. C., and Debrunner, P. G. (1980) Electron nuclear double resonance of iron III cytochrome P450cam. I. Am. Chem. Soc. 102, 1167-1170.

(57) Davydov, R., Dawson, J. H., Perera, R., and Hoffman, B. M. (2013) The use of deuterated camphor as a substrate in H-1 ENDOR studies of hydroxylation by cryoreduced oxy $\mathrm{P} 450$ cam provides new evidence of the involvement of compound I. Biochemistry 52, 667671.

(58) Scholes, C. P., Feher, G., and Isaacson, R. A. (1972) Electron neutron double-resonance studies on heme proteins - Determination of interaction of $\mathrm{Fe} 3+$ with its ligand nitrogens in metmyoglobin. Biochim. Biophys. Acta, Protein Struct. 263, 448-452.

(59) Fann, Y. C., Gerber, N. C., Osmulski, P. A., Hager, L. P., Sligar, S. G., and Hoffman, B. M. (1994) ENDOR determination of heme ligation in chloroperoxidase and comparison with cytochrome P450cam. I. Am. Chem. Soc. 116, 5989-5990.

(60) Davydov, R., Makris, T. M., Kofman, V., Werst, D. E., Sligar, S. G., and Hoffman, B. M. (2001) Hydroxylation of camphor by-reduced oxy-cytochrome P450cam: Mechanistic implications of EPR and ENDOR studies of catalytic intermediates in native and mutant enzymes. I. Am. Chem. Soc. 123, 1403-1415.

(61) Scholes, C. P., Falkowski, K. M., Chen, S., and Bank, J. (1986) Electron nuclear double-resonance (ENDOR) of bis(imidazole)ligated low-spin ferric heme systems. $\underline{\text { I. Am. Chem. Soc. }}$ 108, 16601671.

(62) Uno, T., Nishimura, Y., Makino, R., Iizuka, T., Ishimura, Y., and Tsuboi, M. (1985) The Resonanace Raman frequencies of the Fe-CO stretching and bending modes in the CO complex of cytochrome P450 cam. L. Biol. Chem. 260, 2023-2026.

(63) Mak, P. J., Denisov, I. G., Grinkova, Y. V., Sligar, S. G., and Kincaid, J. R. (2011) Defining CYP3A4 structural responses to substrate binding. Raman spectroscopic studies of a nanodisc- incorporated mammalian cytochrome P450. I. Am. Chem. Soc. 133, $1357-1366$

(64) Spiro, T. G., Soldatova, A. V., and Balakrishnan, G. (2013) CO, $\mathrm{NO}$ and $\mathrm{O}-2$ as vibrational probes of heme protein interactions. Coord. Chem. Rev. 257, 511-527.

(65) Collman, J. P., Sorrell, T. N., Dawson, J. H., Trudell, J. R., Bunnenberg, E., and Djerassi, C. (1976) Magnetic circular dichroism of ferrous carbonyl adducts of cytochromes P450 and P420 and their synthetic models - Further evidence for mercaptide as 5th ligand to iron. Proc. Natl. Acad. Sci. U. S. A. 73, 6-10.

(66) Wells, A. V., Li, P. S., Champion, P. M., Martinis, S. A., and Sligar, S. G. (1992) Resonance Ramans investigations of Eschericia coli expressed Pseudomonas putida cytochrome P450 and P420. Biochemistry 31, 4384-4393.

(67) Sabat, J., Stuehr, D. J., Yeh, S. R., and Rousseau, D. L. (2009) Characterization of the proximal ligand in the P420 form of inducible nitric oxide synthase. I. Am. Chem. Soc. 131, 12186-12192.

(68) Cheesman, M. R., Zumft, W. G., and Thomson, A. J. (1998) The MCD and EPR of the heme centers of nitric oxide reductase from Pseudomonas stutzeri: Evidence that the enzyme is structurally related to the heme-copper oxidases. Biochemistry 37, 3994-4000.

(69) Dhawan, I. K., Shelver, D., Thorsteinsson, M. V., Roberts, G. P., and Johnson, M. K. (1999) Probing the heme axial ligation in the COsensing CooA protein with magnetic circular dichroism spectroscopy. Biochemistry 38, 12805-12813.

(70) McKnight, J., Cheesman, M. R., Thomson, A. J., Miles, J. S., and Munro, A. W. (1993) Identification of charge-transfer transitions in the optical spectrum of low-spin ferric cytochrome P-450 Bacillus megaterium. Eur. I. Biochem. 213, 683-687.

(71) Gadsby, P. M. A., and Thomson, A. J. (1990) Assignment of the axial ligands of ferric ion in low-spin hemoproteins by near-infrared magnetic circular dichroism and electron paramagnetic resonance spectroscopy. I. Am. Chem. Soc. 112, 5003-5011.

(72) Sono, M., Dawson, J. H., and Hager, L. P. (1984) The generation of a hyperporphyrin spectrum upon thiol binding to ferric chloroperoxidase - Further evidence of endogenous thiolate ligation to the ferric enzyme. J. Biol. Chem. 259, 3209-3216.

(73) Bradley, J. M., Marritt, S. J., Kihlken, M. A., Haynes, K., Hemmings, A. M., Berks, B. C., Cheesman, M. R., and Butt, J. N. (2012) Redox and chemical activities of the hemes in the sulfur oxidation pathway enzyme SoxAX. I. Biol. Chem. 287, 40350-40359.

(74) Nguyen, T. A., Jo, M. H., Choi, Y. G., Park, J., Kwon, S. C., Hohng, S., Kim, V. N., and Woo, J. S. (2015) Functional Anatomy of the Human Microprocessor. Cell 161, 1374-1387.

(75) Kwon, S. C., Nguyen, T. A., Choi, Y. G., Jo, M. H., Hohng, S., Kim, V. N., and Woo, J. S. (2016) Structure of Human DROSHA. Cell 164, 81-90.

(76) Driscoll, M. D., McLean, K. J., Levy, C., Mast, N., Pikuleva, I. A., Lafite, P., Rigby, S. E. J., Leys, D., and Munro, A. W. (2010) Structural and Biochemical Characterization of Mycobacterium tuberculosis CYP142. I. Biol. Chem. 285, 38270-38282.

(77) Daff, S. N., Chapman, S. K., Turner, K. L., Holt, R. A., Govindaraj, S., Poulos, T. L., and Munro, A. W. (1997) Redox control of the catalytic cycle of flavocytochrome P-450 BM3. Biochemistry 36, 13816-13823.

(78) Spiro, T. G., and Wasbotten, I. H. (2005) CO as a vibrational probe of heme protein active sites. I. Inorg. Biochem. 99, 34-44. 